\title{
ARTICULAÇÕES ENTRE DIREITO, CIDADE, CULTURA E NATUREZA: RUPTURAS E CONEXÕES JOINTS BETWEEN LAW, CITY, CULTURE AND NATURE: BREAKS AND CONNECTIONS
}

\author{
Allan Sinclair ${ }^{1}$ \\ Ronaldo Lobão ${ }^{2}$
}

\begin{abstract}
A cidade está no centro do mundo e, ao mesmo tempo, o domina. O Tempo do universo flui por meio da cidade e se confunde com o tempo da cidade. Outras genealogias da origem serão inventadas e construídas de modo que cada uma delas transcorra e seja incluída no tempo das filiações. Isto que se construirá será a unidade do tempo das origens no presente. (Tempo, Direito e Memória - Raffaele de Giorgi)
\end{abstract}

\section{Resumo:}

O presente texto procura discutir as possibilidades e os reflexos das relações existentes entre cultura, direito, cidade e natureza a partir de uma possível centralidade por parte da cidade e tendo em vista a predominância da natureza em conflitos envolvendo a proteção de populações tradicionais, grupos quilombolas e indígenas no tocante a sua reprodução cultural.

Palavras-chave: natureza - cidade - cultura - direito - populações tradicionais.

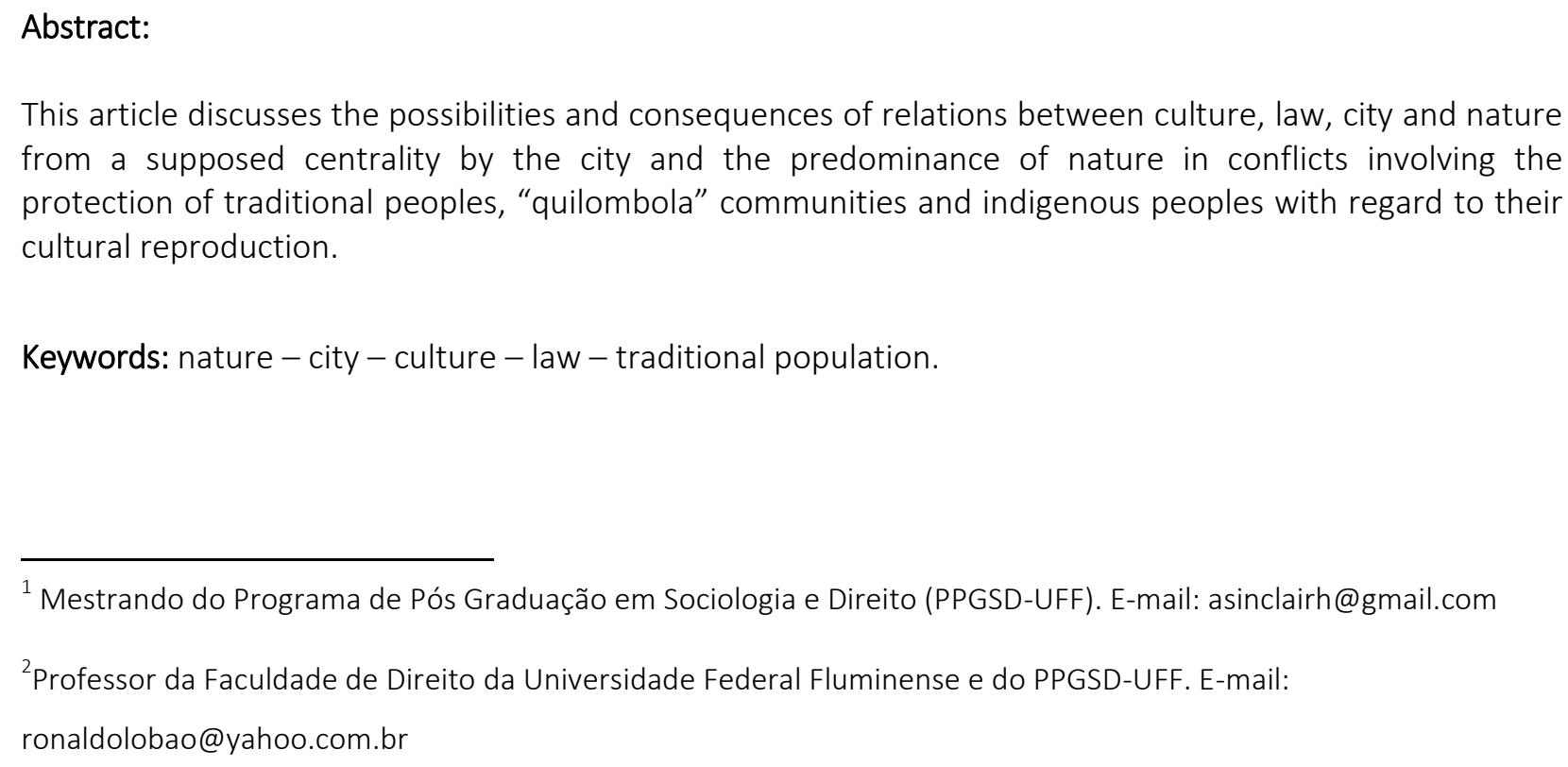

This article discusses the possibilities and consequences of relations between culture, law, city and nature from a supposed centrality by the city and the predominance of nature in conflicts involving the protection of traditional peoples, "quilombola" communities and indigenous peoples with regard to their cultural reproduction.

Keywords: nature - city - culture - law - traditional population.

\footnotetext{
${ }^{1}$ Mestrando do Programa de Pós Graduação em Sociologia e Direito (PPGSD-UFF). E-mail: asinclairh@gmail.com

${ }^{2}$ Professor da Faculdade de Direito da Universidade Federal Fluminense e do PPGSD-UFF. E-mail:

ronaldolobao@yahoo.com.br
} 


\section{INTRODUÇÃO}

Em um contexto globalizante, cada vez mais ganham espaço no âmbito das Ciências Sociais e, particularmente no Direito, as discussões acerca das relações existentes entre Direito, Cidade e Natureza. O que se percebe por vezes é que no desenvolvimento das possíveis formas de interação entre estes, a Cultura enquanto elemento, de algum modo constitutivo e presente neste universo, também funciona como interprete da Cidade, da Natureza e do próprio Direito. Assim, pensamos que através do conceito de Cultura é possível compreender melhor como se dão estas relações e de que forma a sua (des)consideração pode vir a alterar o espectro sócio-jurídico no contexto dos conflitos existentes entre estes lugares e seus atores locais.

O papel predominante da Natureza e da Cidade, principalmente no âmbito de uma análise jurídica, deixa de lado alguns elementos que, caso analisados a partir do prisma da Cultura, poderiam de algum modo trazer novos elementos eclipsados por um certo rigor técnico/científico. Tal característica se traduz na centralidade dada à Cidade e à Natureza nos conflitos envolvendo os direitos populações tradicionais, grupos quilombolas e indígenas no que diz respeito a sua reprodução cultural nos seus lugares tradicionalmente ocupados.

\section{ARTICULAÇÕES DIREITO-CIDADE}

Inicialmente analisaremos as articulações entre direito e cidade, tendo como referência o livro de Raffaele Di Giorgi, "Tempo, direito e memória”, no qual foi feira uma vinculação dessas categorias tendo a Cidade como polo central. Provocados por Di Giorgi, que afirma que a Cidade está no centro do mundo, podemos pensar que a expressão cidadão vem claramente desse universo da cidade e é desse lugar, da cidade, do urbano, que quer queiramos quer não, a Natureza foi capturada, ou projetada, no universo legal, ou em outros termos, positivada.

O próprio Direito Ambiental, fruto de um a interpretação e potência constituidora urbana, acaba por se traduzir em uma projeção sobre a Cidade, sobre o Meio Ambiente e sobre a Natureza. Dentro desta perspectiva, todo o conteúdo sobre a Cultura, sobre os direitos culturais que possa existir no ordenamento positivo, também tem for origem este lugar. Neste sentido, poderíamos afirmar, por

\footnotetext{
${ }^{3}$ DE GIORGI, Raffaele. Direito, tempo e memória. São Paulo: Quartier Latin, 2006.
} 
exemplo, que um campo jurídico como os Direitos Reais, é totalmente informados pelos conceitos de propriedade, contrato e herança urbanas.

Por outro lado, na dimensão empírica, temos exemplos diversos, como as múltiplas formas como se efetiva a transmissão patrimonial em favelas no Rio de Janeiro, descritas por Alexandre Weber (2012) e nenhuma delas em conformidade com o Direito Civil, Direito Urbanístico, Direito Tributário ou outro. Uma moradia de sala e dois quartos pode ser divida em duas e os donos podem vender apenas um quarto a outra pessoa, se assim decidirem.

No sul de Minas Gerais, conforme um pequeno livro de Margarida Maria Moura (1978), uma herança não seria dividida entre todos os herdeiros de um pequeno sítio rural, pois tal divisão, nos moldes do direito civil e, portanto, nos moldes urbanos, não seria capaz de garantir a subsistência de cada família. O direito costumeiro de legar a apenas um herdeiro, em geral aquele que ficou tomando conta dos pais, é fruto de uma tradição cultural que leva em consideração a capacidade de sustento advindo do cultivo da terra, pois uma fração de apenas 10 por cento de um sítio rural que sustentou dez filhos não seria capaz de continuar com sua função social local.

O Direito não tem capacidade cognitiva de reconhecer estas práticas como legítimas pois não são as da Cidade, apesar de podermos também pensar que, dentro da própria cidade não se segue estritamente as práticas oriundas do direito civil. Em Niterói, por exemplo, no Bairro do Ingá, a Faculdade de Direito se localiza em frente a comunidade do Morro do Palácio, e lá certamente toda a positivação dos direitos reais, não acontece. Atividades como a compra, venda e aluguel, são totalmente transacionadas à margem das regras do direito positivo.

A Cidade portanto apesar de estar no centro do mundo, não representa, efetivamente, o mundo. O Estado, coloca com o auxílio do Direito, a Cidade como referência, criando assim um imaginário daquilo que deveriam ser as práticas que se estabeleceriam entre os diversos atores sociais em todas as localidades, mas não o que realmente não acontece. ${ }^{4}$

Paul Virilio, arquiteto que trabalhou essas articulações entre Direito e Cidade, em num livro chamado "Velocidade e política" ${ }^{5}$, apresentou uma discussão interessante sobre o que chamou de "dromologia", ou seja, o culto à velocidade, a importância da velocidade, dos fluxos, para a administração

\footnotetext{
${ }^{4}$ Ver BOURDIEU, Pierre. O poder simbólico. Tradução de Fernando Tomaz. 14ạ Ed. Rio de Janeiro: Bertrand Brasil, 2010.

${ }^{5}$ VIRILLIO, Paul. Velocidade e Política (Vitesse et Polítique). São Paulo, Estação Liberdade, 1997.
} 
do bem-estar da sociedade contemporânea. Afirmou, de forma um tanto quanto provocativa que, nos dias de hoje, não é a democracia que impera nas relações sociais presentes na Cidade e sim a "Dromologia", ou seja, um culto à velocidade, percorrer maiores distâncias em menos tempo.

Deste modo, se reconstruirmos ideologia fundante das transformações da Cidade no século XIX e ao longo do século $X X$, chegaremos a conclusão que a ideia do higienismo nas cidades se traduziria adequadamente na ideia dos fluxos rápidos. As reformas urbanísticas de Pereira Passos ${ }^{6}$ e de Saturnino de Brito $^{7}$ na cidade do Rio de Janeiro consistiram na retificação da Cidade e dos canais pluviais. Estas reformas também tomaram como solução, pelo menos teoricamente, para a saúde das lagunas do Norte Fluminense ou mesmo da Lagoa Rodrigo de Freitas na cidade do Rio de Janeiro, a abertura de canais com ligações estreitas para o mar.

Com o tempo, os resultados não foram tão positivos, apesar de momentaneamente bem sucedidos. Os fluxos rápidos da Cidade podem ter sido alcançados por um lapso de tempo, mas com o passar do tempo, em termos ambientais, a retificação de rios, canais, lagoas, passagens e essa renovação rápida de fluxos do mar, não se concretizou, ou alterou a constituição dos espaços originais, transformouos em outra coisa que não eram. De fato, podemos afirmar que a imagem da Cidade, que está intimamente ligada à imagem do Direito, e vice versa, não consegue solucionar adequadamente desafios ambientais e culturais.

\section{ARTICULAÇÕES DIREITO E NATUREZA}

\footnotetext{
${ }^{6}$ A reforma empreendida pelo prefeito, do então Distrito Federal, Francisco Pereira Passos, visava eliminar, sobretudo, as contradições do espaço urbano carioca. Era preciso que a cidade assumisse novas feições de acordo com as determinações econômicas e ideológicas do momento. Era de urgência agilizar a circulação de mercadorias, que pendia devido às características do espaço colonial da cidade. Tendo, então, a cidade cortada em todos os sentidos, afetando lugares e a vida das pessoas. O Rio de Janeiro tinha que se tornar uma nova capital moderna, que simbolizasse realmente a importância do Brasil e fosse expressão dos valores e modos de vida cosmopolita e moderna da elite do país. Passos, apoiado pelos setores dominantes da sociedade, estabeleceu seu plano dando início ao "bota-abaixo", começando a realizar as obras de embelezamento e saneamento da cidade.

${ }^{7}$ A abertura da Avenida Epitácio Pessoa em torno da Lagoa Rodrigo de Freitas e a construção de dois canais para saneamento da lagoa, respectivamente o de comunicação com o mar no Jardim de Alah e o interceptador da Avenida Visconde de Albuquerque destinado a recolher águas pluviais da vertente da Serra do Corcovado, desviando da lagoa as águas doces que passaram a ser diretamente conduzidas ao mar foram projetados por Saturnino Rodrigues de Brito.
} 
O desafio das relações entre Direito e Natureza foi trabalhado na contribuição do jurista belga François Ost, em seu livro de título sugestivo "A natureza à margem da lei", 8 onde trata de vários desafios que envolvem a concepção e construção dos conceitos de Natureza e Meio Ambiente e das relações destes com o Direito. O antropólogo brasileiro Antônio Carlos Diegues trabalhou esta questão a partir do que chamou de "mito da natureza intocada" ${ }^{9}$, no qual é necessário uma separação radical entre Natureza e Cultura.

A ideia central de Ost trata da dificuldade do Direito ou da Lei incorporar as múltiplas representações da Natureza, o que implica em novo desafio para uma tradução necessária entre as visões da Ecologia e a visão do Direito. Para Ost, visão que os autores do campo disciplinar Ecologia se estrutura numa lógica de conceitos englobantes e evolutivos, ou seja, para a Ecologia, o espaço tem uma dimensão geral. A Natureza, o Meio Ambiente, o Bioma, a Espécie, são representações globalizantes.

Para a Ecologia os conceitos são absolutamente englobantes, porém dentro de uma ideia de evolução, de constante transformação uma vez que determinados recursos desaparecem e aparecem posteriormente em outros lugares No norte fluminense, por exemplo, em 2000 a sardinha desapareceu na região costeira de Campos e surgiu uma outra espécie, o peruá. Três anos depois, o peruá desapareceu, mas nada apareceu no lugar, gerando uma crise no setor da pesca artesanal local. Ou seja, há processos que, apesar de seus efeitos locais, não são determinados localmente. Entretanto o Direito tem a necessidade de estabelecer categorias fixas e especializadas, que pretendem segmentar o real. Tanto o Direito Ambiental quanto as Ciências Naturais em geral almejam um alto grau de precisão e previsibilidade.

Nas relações Ecologia e Direito, no que diz respeito ao Direito Ambiental, em países de culturas jurídicas distintas, as relações que se estabelecem com os recursos naturais são diferentes. O Direito Ambiental brasileiro, argentino e uruguaio são exemplo disto. Por exemplo, um recurso natural marinho renovável, o peixe - rés nullius enquanto nada no mar e propriedade privada do pescador que o pescar segundo o Direito brasileiro - pode estar na Argentina, em movimento, nadando, passando por onde o

${ }^{8}$ OST, François. A natureza à margem da lei: a ecologia à prova do direito. Trad. Joana Chaves. Lisboa: Instituto Piaget, 1997.

${ }^{9}$ DIEGUES, A. C. O mito moderno da natureza intocada. São Paulo: Hucitec, 1999.

Revista de Direito da Cidade, vol.06, no02. ISSN 2317-7721 p. 492-506 496 
Direito Ambiental argentino constitui determinada concepção de gestão de recursos marinhos, claramente determinada por sua importância econômica no Produto Interno Bruto argentino.

Porém quando este mesmo peixe passa pelo Uruguai, que não tem regulamentação sobre este tipo de recurso, não reflete nenhuma representação jurídica sobre si. Porém, ao chegar ao Brasil constituirá nova relação com os pescadores e biólogos marinhos, que conformarão outro ordenamento jurídico pois apesar do peixe ser o mesmo, as representações sobre ele são distintas. No mar, entretanto, pescadores argentinos, uruguaios e brasileiros atuam sobre este recurso em conformidade com as mesmas regras de captura e valores - culturais e econômicos - sem levar em conta limites jurídicos e fronteiras territoriais.

A Ecologia também utiliza outra definição temporal que dialoga com as observações de Paul Virilio $^{10}$. Que os sistemas ambientais, os sistemas naturais seriam todos eles fruto de um processo de longa duração. Algo que façamos hoje pode vir a gerar um impacto muito mais adiante do que numa dimensão temporal de causa e efeito, apesar de muitas vezes não conseguirmos perceber essa relação de causalidade, sobre o que poderia estar provocando, por exemplo, uma determinada degradação ambiental. A perda de determinada biodiversidade em momento determinado, pode ser fruto de outras intercorrências anteriores, temporalmente afastadas, regidas por um processo de adaptação, necessariamente complexa e não de causalidade direta. Ou seja, um sistema natural tem mecanismos que conseguem reproduzir e se adaptar às novas situações, às vezes se adaptando bem, às vezes se adaptando mal, incluindo uma nova variável no sistema que corresponde a um aprendizado, conforme propôs John H. Holland para os sistemas adaptativos complexos (1996).

Um exemplo clássico da imprevisibilidade do manejo de recursos naturais renováveis foi a gestão dos jacarés do Pantanal Matogrossense. A legislação ambiental (Lei de Crimes Ambientais de 1998) proibiu a pesca ou a caça do jacaré e o ecossistema respondeu da pior forma possível. E, apenas uma década, houve uma superpopulação de jacarés, fruto de um desequilíbrio ecológico, pois diminuíram as presas do jacaré e este não tinha mais nenhum predador. Duas consequências nefastas: o jacaré passou a ser o predador do próprio jacaré e ter o homem como presa, uma vez que o homem que não pode, legalmente, ser o predador do jacaré.

\footnotetext{
${ }^{10}$ Idem
} 
Uma vez que esses processos são complexos, adaptativos e de longa duração, vemos que a Ecologia tem dificuldade em informar adequadamente o Direito, que almeja a simplicidade, a causalidade e os ritmos curtos, na escala das previsões humanas, para comandar a salvação do jacaré. Os ecólogos sugerem a liberação da caça ao jacaré, ou seja, a reintrodução de um predador do jacaré no ecossistema. Mas essa recomendação é "ilegal" pois o Direito não têm abertura cognitiva para dar sentido a um processo complexo e adaptativo, que implica, necessariamente, em aprendizado constante. No campo do Direito todos se veem ameaçados com pela ideia da imprevisibilidade e da insegurança - física e jurídica.

O Direito do Ambiente, portanto, como obra de juristas, não compreende o complexo e o variável, já nos disse François Ost. É nesta perspectiva que se pode afirmar que a Natureza estaria à margem da lei. Em outro sentido, não é a Natureza concreta que corresponde à Natureza que pretende ser tutelada pelo Direito. O Direito se dirige a uma outra representação que não corresponde, necessariamente, ao do espaço natural concreto. Para não ser assim, o conceito jurídico de Natureza teria necessariamente que incorporar a complexidade e a variabilidade como sua composição e não teria a necessária fixidez, obrigatória para que o Direito represente aquilo que chama de Natureza.

\section{ARTICULAÇÕES DIREITO E CULTURA}

Outra articulação então, é necessária, pois quando falamos desse "Direito da Natureza" falamos também de Cultura e uma visão sobre o conceito de Cultura pensado de uma forma muito ampla. Podemos pensar, por exemplo, que os antropólogos têm uma Cultura antropológica, porque são socializados em determinados campos disciplinados, conformados por práticas e situações concretas e desenvolvem métodos particulares, ou uma Cultura própria. A partir da mesma lógica os bacharéis em Direito, os juristas, também constroem o seu campo, mas de um ponto de vista diverso, que recusa a empiria, o que acaba por conformar uma Cultura jurídica.

Por exemplo, Deborah Duprat Pereira, procuradora do Ministério Público Federal, defendeu que Constituição Federal Brasileira de 1988 reconheceu o Brasil como um estado pluriétnico. ${ }^{11}$ Ela se baseou, basicamente, em três artigos do corpo permanente da Constituição, os artigos 215 e 216 que tratam de direitos culturais e do artigo 231, que trata dos direitos dos povos indígenas. Se apoiou também no artigo

\footnotetext{
${ }^{11}$ PEREIRA, Deborah Duprat. 2002. O Estado Pluriétnico. In: Além da tutela: bases para uma nova política indigenista III. Rio de Janeiro: Contra Capa Livraria.
} 
68 do Atos das Disposições Constitucionais e Transitórias, que determina a titulação permanente da propriedade dos remanescentes de quilombos.

A partir desse conjunto de dispositivos da Constituição, sem nenhuma correlação empírica, a autora afirmou que a sociedade brasileira e a Constituição Brasileira não mais reconhecem apenas uma unicidade nacional, ou seja, se filiam ao modelo de Estado que foi construído ao longo do século XIX - o Estado-Nação. Não haveria uma única nação, o que implica em uma única filiação, um único sentimento de pertencimento, de todos os que ocupam as fronteiras do país. Entretanto, dentro dos limites dessas fronteiras um único Direito deve ser reconhecido. Afirmou que, com o advento da Constituição de 1988, estaríamos sobre a vigência de um novo Estado, o Estado Pluriétnico, porém ser monista em seu Direito. O Direito aceito seria apenas aquele advindo do Estado, apesar do reconhecimento, por parte do Estado, de múltiplas etnias no interior de suas fronteiras.

Entretanto, essas etnias, passariam a ter direitos de cidadania diferenciados dentro desse Direito monista, ou seja, poderiam reivindicar direitos distintos dos demais direitos da sociedade envolvente, porém concedidos ou limitados pelo Direito desta.

Esse arranjo pode, evidentemente, ser manipulado tanto de um lado quanto de outro, mas é importante destacarmos que há autores e operadores do campo do Direito que passaram a trabalhar a partir dessa perspectiva. Um exemplo do uso desses conceitos, que associou o conceito de Cultura com, por exemplo, o Direito Ambiental foi um parecer da Procuradora, também do Ministério Público Federal, Maria Luiza Grabner ${ }^{12}$, sobre um conflito socioambiental no Parque Estadual da Serra do Mar, em São Paulo.

No parecer, a procuradora afirma que no contexto local, os direitos culturais de caiçaras e quilombolas que lá vivem, se sobrepujariam ao Direito Ambiental no que se refere ao imperativo determinado pela Lei n.o 9.985/2000, que criou o Sistema nacional de Unidades de Conservação, para a desintrusão do parque dos caiçaras e dos quilombolas. Isso porque as Unidades de Proteção Integral consagradas pelo SNUC ${ }^{13}$, não permitem presença humana permanente em seu interior. Grabner associou o conceito do Estado Pluriétnico, reconheceu a precedência de determinados direitos culturais, não só

\footnotetext{
${ }^{12}$ GRABNER, Maria Luiza. S.d. Recomendação PRM/SJC no 01/03 - Meio Ambiente e Minorias/SOTC. Disponível em http://www.abdl.org.br/filemanager/fileview/50/

${ }^{13}$ Lei n.o 9.985, de 18 de julho de 2000 (Lei do SNUC)
} 
como direitos do grupo em si, direitos coletivos, mas como direitos dotados de repercussão para toda a sociedade.

Com essa autora, defendemos que nos marcos do Direito contemporâneo e da formação da sociedade brasileira, que os direitos culturais não são apenas direitos do grupo específico local, seja quilombola, seja índio, seja caiçara. Estes direitos seriam direitos da sociedade nacional que, ao se reconhecer como plural, entendeu ser necessária a reprodução social, cultural e material autônoma destes grupos.

Deste modo não entendemos os direitos de um grupo remanescente de quilombo como um direito coletivo daquele grupo, mas defendemos que a reprodução de cada cultura local deve ser assegurada como forma de garantir a reprodução da cultura nacional em sua diversidade constitutiva.

Defendemos que os direitos culturais tem o mesmo estatuto jurídico que os direitos difusos e que ao se confrontarem deve haver uma equivalência de direitos e não uma hierarquização entre eles. Não reconhecemos que o Direito Ambiental, como Direito Difuso estaria em um patamar superior ao Direito Cultural, apesar do parecer da Procuradora defender que este deveria preceder ao Direito Ambiental.

Na direção da efetivação dos direitos culturais, o governo federal promulgou em 2007 o Decreto n.ㅇ 6040 de $2007^{14}$ que estabeleceu uma política de desenvolvimento sustentável de povos e comunidades tradicionais. Neste decreto vemos pela primeira vez uma definição jurídica para o conceito de "população", "povo" ou "comunidade" tradicional, além de definir o conceito de "território" tradicional, central para nossa discussão sobre a relação entre o Direito, Cultura, natureza e, de alguma forma, a Cidade, que também abriga, por mais que possa parecer contraditório, territórios tradicionais.

Devemos destacar que esse conceito - território tradicional -, que o movimento social, antropólogos e o governo têm trabalhado, sofreu forte contestação no julgamento da PET 3.388 pelo Supremo Tribunal Federal (sobre a demarcação da Terra Indígena Raposa Serra do Sol). No voto do Min. Carlos Ayres Britto, "território" corresponde apenas ao espaço soberano do país. O Decreto n.ำ 6040/2007 define inúmeros "territórios tradicionais" que correspondem aos espaços de reprodução de comunidades tradicionais, que por sua vez podem estar em qualquer lugar. Não apenas em lugares distantes como a Amazônia, no interior do Vale do Jequitinhonha, podem existir na Lagoa Rodrigo de

14 Decreto 6.040, de 07 de fevereiro de 2007 (Institui a Política Nacional do Desenvolvimento Sustentável dos Povos e Comunidades Tradicionais).

Revista de Direito da Cidade, vol.06, n0.02. ISSN 2317-7721 p. 492-506 500 
Freitas, pode estar em Niterói, à beira da praia de Itaipu, pode corresponder a uma somatório de lugares distantes entre si ou descontínuos.

O conceito de comunidade tradicional e de território tradicional estão presentes em vários instrumentos de gestão de política fundiária e de conservação da Natureza, como as Reservas Extrativistas, ou o Termo de Autorização de Uso Sustentável, que a Secretaria do Patrimônio da União celebra como forma de fixação de comunidades tradicionais em áreas da União.

Tudo isso permite afirmar que esses conceitos estão imbricados aos de Meio Ambiente, Natureza e Cultura. Em espaços naturais ou modificados pelo homem. Estão também nas Cidades e, portanto, devem estabelecer um diálogo fértil com os Planos Diretores de inúmeros municípios brasileiros. .

\section{RUPTURAS ENTRE DIREITO E CIDADE, DIREITO E NATUREZA, DIREITO E CULTURA}

Os contextos que inspirara, nossas ideias correspondem a contextos conflitivos, mais especificamente conflitos socioambientais, descreveremos brevemente três casos, uma vez que o que nós vimos aqui até agora correspondem às possibilidades e as dificuldades da articulação entre Direito e Cidade, Direito e Natureza, Direito e Cultura. De fato, nos debruçaremos sobre possíveis articulações acerca das rupturas entre Direito e Cidade, Direito e Natureza, Direito e Cultura.

O primeiro caso tem como lugar o Quilombo do Sacopã, ou Quilombo da Família Pinto, na Lagoa Rodrigo de Freitas, no Rio de Janeiro. Esse é um processo, digamos, desafiante cognitivamente e emocionalmente. Não se trata de um grupo que "sobrou" da favela da Catacumba. Eles se ocupam uma área de sete mil metros quadrados na Rua Sacopã, desde 1930. A família Pinto já foi reconhecida pela Fundação Cultural Palmares como remanescente de quilombo, o Instituto Nacional de Colonização e Reforma Agrária (INCRA) já reconheceu a propriedade definitiva dos remanescentes de quilombo do Sacopã, através do Relatório Técnico de Identificação e Delimitação (RTID-INCRA) correspondente. Esta delimitação tem implicações maiores, pois parte da ocupação tradicional dos quilombolas estar, desde 2000, sobreposta ao Parque Natural Municipal José Guilherme Melchior, unidade de proteção integral pelo SNUC, e em tensão jurídica com as restrições do zoneamento urbano da cidade do Rio de Janeiro..

Apesar dos procedimentos administrativos preconizados pelo Decreto Federal n.․ 4.887, de 20 de novembro de 2003, terem sido concluídos os direitos dos remanescentes de quilombos não consegue ser efetivado. Isso porque, o município do Rio de Janeiro ainda não concluiu a elaboração de dispositivos 
legais que permitam faze-lo. O Governo Federal também não pode emitir o título, apesar da previsão constitucional permitir a concessão "dos respectivos títulos", que se encontra no artigo 68 do ADCT, porque parte do quilombo ocupa área pública municipal.

Houve avanços com a aprovação no Plano Diretor do Município do Rio de Janeiro, Lei Complementar Municipal n.o 111/2011, das Áreas de Especial Interesse Cultural (AEIC), são destinada "a afetação dos Sítios Culturais, definidos no art. 140 desta Lei Complementar, por conservar referências ao modo de vida e cultura carioca, necessária à reprodução e perpetuação dessas manifestações culturais" (Rio de Janeiro, art. 70, inciso VII).

Mas isso não basta, porque está tudo e ao mesmo tempo separado. Nós temos um parque, mas ao mesmo tempo uma propriedade quilombola, nós temos um Estatuto da Cidade, e ao mesmo tempo temos direitos culturais. Mas no fim o interessante seria pensar de que forma estas relações funcionam ou será que não funcionam?

Outro caso semelhante, é o da Comunidade Tradicional do Morro das Andorinhas, que ocupa o topo do Morro das Andorinhas, na cidade de Niterói, separando a praia de Itaipu da praia de Itacoatiara. A comunidade corresponde a uma família que habita este lugar desde o século XIX. Durante quase 20 anos a família, hoje "comunidade", resistiu para permanecer em seu lugar tradicional, a partir do momento que sua ocupação se tornou "visível" ao mundo oficial do Direito com a abertura pelo Ministério Público Estadual (MPE) de Inquérito Civil para apurar eventuais danos ao Meio Ambiente em Área de Proteção Permanente (APP) do Município e classificada ambientalmente como Mata Atlântica.

Depois da instalação, em 2002, de uma Ação Civil Pública (ACP) para a remoção da comunidade, violências físicas simbólicas foram cometidas e rechaçadas através da parceria da comunidade com pesquisadores da Universidade Federal Fluminense (UFF). A ACP teve fim, com a ressignificação por parte do MPE quanto a ocupação do Morro pela família, que foi considerada como comunidade tradicional em 2005.

Em 2007, nova investida do mundo jurídico ocorreu com a anexação do Morro das Andorinhas ao Parque Estadual da Serra da Tiririca (PESET). A partir de então a comunidade passou a ocupar não só uma APP, mas também uma unidade de proteção integral segundo o SNUC. Novas investidas contra sua permanência foram encetadas.

Revista de Direito da Cidade, vol.06, no⒉ ISSN 2317-7721 p. 492-506 502 
Em 2011, o Ministério Público Federal, em sede de outra ACP, desta feita contra um condomínio de classe média alta localizado na encosta de Itacoatiara, recomenda à Prefeitura a demolição da "favela" existente no topo do morro, ou seja a Comunidade Tradicional do Morro da Andorinhas. As discussões no Congresso Nacional sobre o novo Código Florestal (aprovado em 2013) chamaram a atenção para o local topo do morro - e uma perícia judicial havia classificado a comunidade como favela.

Essas rupturas são exatamente o que proporciona o que se pode chamar, para usar um conceito de François Ost em outro livro, Contar a Lei, as fontes do imaginário jurídico (2005), de distopia, ou seja, uma realidade produzida pelo Direito que se apresenta distorcida, que não corresponde adequadamente nem a estabilidade, nem a mudança. Ou não é compreendida de forma segura, nem pelo atores que a produzem nem por aqueles que são seus produtos.

Tais distopias correspondem ao Direito de uma Cidade não tem previsão para efetivação do direito Cultural, materializado em uma propriedade para uma comunidade de remanescente de quilombo, conforme previsão constitucional. Corresponde ao imbricamento de competências entre as esferas e instituições do Direito que sobrepõem dispositivos e procedimentos desconectados uns dos outros. Pode ser evidenciada na ausência de legislação que permita se fazer um ordenamento diferenciado sob o prisma da preservação cultura, deste modo acabamos por ter diversos obstáculos e diversas tentativas de resolver isso, onde toda vez que o processo segue adiante surge algum novo entrave jurídico/político.

Por fim, outra grande disputa pode ser exemplificada a partir do município de Niterói, mas que pode ser estendida para toda a costa brasileira, que corresponde às disputas pelo uso das terras e do mar ao longo da costa brasileira. A forma como pensamos a costa no Rio de Janeiro, ou a praia de Copacabana, serviria de modelo para todo o litoral brasileiro? É possível pensar em um modelo único?

Podemos pensar em vários lugares em que chegamos onde o modelo de Copacabana e Ipanema isto é, uma avenida com carros trafegando separando as habitações para o aceso ao mar - foi intencionalmente recusado. Por exemplo, no extremo sul da Bahia, a cidade de Alcobaça, entre Caravelas e Prado, tem como atrativo não sua "Avenida Atlântica", mas uma urbanização do litoral que recusou a Avenida Atlântica. Este modelo de urbanismo traduziria essa ideia do prédio, da avenida e do mar colocados positiva ou negativamente. Alcobaça é um lugar em que se vende a idéia de não ser uma Avenida Atlântica, ou seja de que o fato das casas estarem em frente à praia, é estar diretamente na praia, para o bem ou para o mau.

Revista de Direito da Cidade, vol.06, no⒉ ISSN 2317-7721 p. 492-506 503 
Mas o que testemunhar e ao longo dos municípios costeiros do Estado do Rio de Janeiro, da Bahia e certamente em vários outros estados, estamos perdendo os lugares tradicionais de ocupação cultural e histórico na beira da praia. Vários lugares que dizem respeito a toda nossa trajetória, em um país que foi povoado pelo mar estão ocultando sua história, sua memória, sua Cultura, em lugares distante do mar e colocando nestes lugares outra forma de ocupar a orla que está absolutamente voltada pra outros tipos de interesses.

Quem anda pelo extremo sul da Bahia verá que uma vila, que foi indígena há algum tempo, que passou a ser ocupada em conjunto com pescadores artesanais, como Caraíva, se transforma num grande resort de interesses internacionais. Seis quilômetros mais ao sul, a vila de Corumbau foi tomada por pessoas de fora - Rio de Janeiro, São Paulo - em um processo semelhante, indicando que o próximo passo será a internacionalização de Corumbau.

Entre elas está localizada a Terra Indígena de Barra Velha do Monte Pascoal, ocupada pelo povo Pataxó. Caberia, talvez, o pensamento sobre o que acontecerá quando estes dois povoamentos ganharem estatuto de cidades. Quando legislações municipais poderão alterar o conteúdo e a fruição de direitos culturais.

\section{É POSSÍVEL RELIGAR O DIREITO, CIDADE, CULTURA E NATUREZA?}

Por fim, a dúvida que fica é saber como e se é possível religar o Direito a Cidade, a Cultura e a Natureza. Podemos recorrer a ao juiz francês, Antoine Garapon e um jurista grego, Ioannis Papadopoulos, que escreveram o livro Julgar nos Estados Unidos e na França" ${ }^{15}$. Estes autores lançam como desafio o diálogo entre Culturas para se ter o diálogo entre Direitos, se referindo às disputas entre o Direito Francês e o Direito Inglês.

O texto sugere que deve haver um diálogo mais amplo, mais franco e mais aberto, no Direito, pensado como Ost nos apresentou, em uma Cidade plural, ou seja, os desejos da cidade, o pensamento

${ }^{15}$ GARAPON, Antoine; PAPAPOULOS, Ioannis. Julgar nos Estados Unidos e na França: cultura jurídica francesa e common law em uma perspectiva comparada. Rio de Janeiro: Lumen Juris, 2008.

Revista de Direito da Cidade, vol.06, no02. ISSN 2317-7721 p. 492-506 504 
da cidade, o planejamento da cidade. Nós somos intérpretes da natureza. Infelizmente, por mais que já estejamos pensando o direito das coisas, da natureza, o direito da quinta geração, da sexta geração, as árvores não vão dizer para nós o que elas querem que seja feito com elas, e nós (se não sairmos correndo, porque se a árvore começar a falar nós vamos fugir), continuaremos sendo intérpretes da natureza.

Mas apesar disso no campo da cultura podemos trabalhar diretamente. Não precisamos de antropólogos, não precisamos de juristas, não precisamos de intermediários entre esses grupos para que estes possam falar diretamente o que eles querem que a nossa lei faça. É claro que em alguns momentos, como em certas audiências públicas, pelo menos cognitivamente, auditivamente, o discurso de determinados grupos considerados tradicionais se encontra muito sofisticado. Certa vez uma senhora negra, que ao ser questionada sobre qual era sua identidade numa reunião dessas de relação de governo e políticas públicas, chegou para a facilitadora do evento e disse: "Minha filha, você quer que eu diga o quê? Eu sou mulher, eu sou negra, eu sou quilombola, eu sou quebradeira de coco de babaçu, eu estou na transversalidade identitária."

Neste momento podemos parar, dar uma respirada, e pensar... "bom, aqui o tradicional somos nós." Porque nós, homens modernos podemos não fazer ideia do que seja "transversalidade identitária" enquanto aquela senhora utiliza este discurso com uma tranquilidade muito grande. De qualquer forma, a ideia esta colocada. Para se estabelecer um diálogo, precisamos nos conhecer mutuamente. Deste modo precisamos conhecer os quilombolas da família Pinto, precisamos conhecer a comunidade tradicional do Morro das Andorinhas, antes de dizer que elas têm de sair de lá porque o Código Florestal não permite uma propriedade no topo de morro.

\section{BIBLIOGRAFIA:}

BOURDIEU, Pierre. O poder simbólico. Tradução de Fernando Tomaz. 14a Ed. Rio de Janeiro: Bertrand Brasil, 2010.

DE GIORGI, Raffaele. Direito, tempo e memória. São Paulo: Quartier Latin, 2006.

DIEGUES, A. C. O mito moderno da natureza intocada. São Paulo: Hucitec, 1999.

GARAPON, Antoine; PAPAPOULOS, loannis. Julgar nos Estados Unidos e na França: cultura jurídica francesa e common law em uma perspectiva comparada. Rio de Janeiro: Lumen Juris, 2008. 
GRABNER, Maria Luiza. S.d. Recomendação PRM/SJC no 01/03 - Meio Ambiente e Minorias/SOTC. Disponível em http://www.abdl.org.br/filemanager/fileview/50/

HOLLAND. John H.. Hidden Order: how adaptation builds complexity. Cambridge: PerseusBooks, 1996.

MOURA, Margarida Maria. Os herdeiros da terra: Parentesco e herança numa área rural. São Paulo, Editora Hucitec, 1978.

OST, François. A natureza à margem da lei: a ecologia à prova do direito.. Lisboa: Instituto Piaget, 1997 Contar a lei, as fontes do imaginário jurídico. São Leopoldo, Editora Unisinos, 2005.

PEREIRA, Deborah Duprat. 2002. O Estado Pluriétnico. In: Além da tutela: bases para uma nova política indigenista III. Rio de Janeiro: Contra Capa Livraria

VIRILLIO, Paul. Velocidade e Política (Vitesse et Polítique). São Paulo, Estação Liberdade, 1997.

WEBER, Alexandre. Transmissão de patrimônio habitacional em favelas. Niterói, Editora da UFF, 2012.

Legislação:

BRASIL. Constituição Federal. 1988.

Lei n.o 9.605, de 12 de fevereiro de 1998 (Lei de Crimes Ambientais)

Lei $n$. 9.985, de 18 de julho de 2000 (Lei do SNUC)

Decreto 4.887, de 20 de novembro de 2003 (Define critérios e procedimentos para a identificação e titulação de terras de que trata o Art. 68 dos ADCT da CFRB).

Decreto 6.040, de 07 de fevereiro de 2007 (Institui a Política Nacional do Desenvolvimento Sustentável dos Povos e Comunidades Tradicionais).

RIO DE JANEIRO. Lei Complementar Municipal, n. 111/2011 (Plano Diretor da Cidade do Rio de Janeiro)

Trabalho enviado em 20 de agosto de 2014.

Aceito em 05 de setembro de 2014. 